Case Report

\title{
Cavernous hemangioma of left nasal meatus
}

\section{Anil Hanakere Thimmaiah, Smitha Soubhagya Gangaraj*, Thara Rachel Paul}

\author{
Department of ENT, Kempegowda Institute of Medical Sciences, VV Puram, Bangalore, Karnataka, India
}

Received: 17 March 2019

Accepted: 29 May 2019

\author{
*Correspondence: \\ Dr. Smitha S.G., \\ E-mail: smitha_praveen@hotmail.com
}

Copyright: () the author(s), publisher and licensee Medip Academy. This is an open-access article distributed under the terms of the Creative Commons Attribution Non-Commercial License, which permits unrestricted non-commercial use, distribution, and reproduction in any medium, provided the original work is properly cited.

\begin{abstract}
Hemangiomas are benign accumulations of blood vessels which occur in any tissue that includes vascular components like skin, mucosa, muscles, glands and bones. Hemangiomas arising in the nose are rare and account for less than $20 \%$ of all benign tumors of nose. They usually arise from inferior turbinate, middle turbinate and vomer. We present a case of cavernous hemangioma of left nasal cavity arising from mucosa of left middle meatus mimicking an antrochoanal polyp. Hemangiomas arising from middle meatus are extremely rare and to our knowledge this is the second case reported in literature.
\end{abstract}

Keywords: Hemangioma, Middle meatus, Cavernous

\section{INTRODUCTION}

Hemangiomas are benign accumulations of blood vessels that occur in any tissue that includes vascular components like skin, mucosa, muscles, glands and bones. They are mainly idiopathic in origin. Hemangiomas are classified on the basis of blood vessels they contains into capillary, cavernous, and mixed type. Capillary type is more common compared to cavernous type. They account for less than $20 \%$ of all benign tumors of nose. They usually arise from nasal septum, inferior and middle turbinate. We present a case of cavernous hemangioma of left nasal cavity arising from mucosa of left middle meatus mimicking an antrochoanal polyp. Hemangiomas arising from middle meatus is extremely rare and to our knowledge this is the second case reported in literature. The first case reported was by Archontaki etal in 2008. ${ }^{1}$

\section{CASE REPORT}

28 year old female presented to our OPD with history of gradually progressive left nasal obstruction and nasal mass for the past 6 months. She also complained of recurrent mild epistaxis associated with it. Anterior rhinoscopy showed pinkish mass obscuring whole of the nasal cavity up to the vestibule which bleeds on probing.
The right nasal cavity was normal. On posterior rhinoscopy mass was seen protruding through left posterior choana into the nasopharynx. Routine blood investigation was done which showed microcytic hypochromic anaemia. Contrast enhanced CT scan revealed soft tissue mass showing heterogeneous attenuation and moderate nonhomogeneous enhancement filling the left nasal cavity extending into nasopharynx (Figure 1). There was no evidence of adjacent bone destruction. Multiple enhancing vascular channels were seen traversing the mass predominantly in the nasal component suggestive of angiomatous antrochoanal polyp. Through trans nasal endoscopy under general anaesthesia the pedicle of the mass was noted arising from the middle meatus near the anterior fontanelle (Figure 2). The pedicle and part of surrounding mucosa was cauterized. The growth was removed enmass and sent for histopathological examination (Figure 3). Histopathological examination of the specimen revealed cavernous hemangioma with ulceration of surface mucosa. Thin walled blood vessels with necrosis and thrombi, hemosiderin laden macrophages typical of hemangioma was noted (Figure 4).

Patient had an uneventful postoperative period. Anterior nasal pack was removed after two days and patient was 
discharged. Patient came for routine follow up and there is no evidence of residual or recurrent disease.

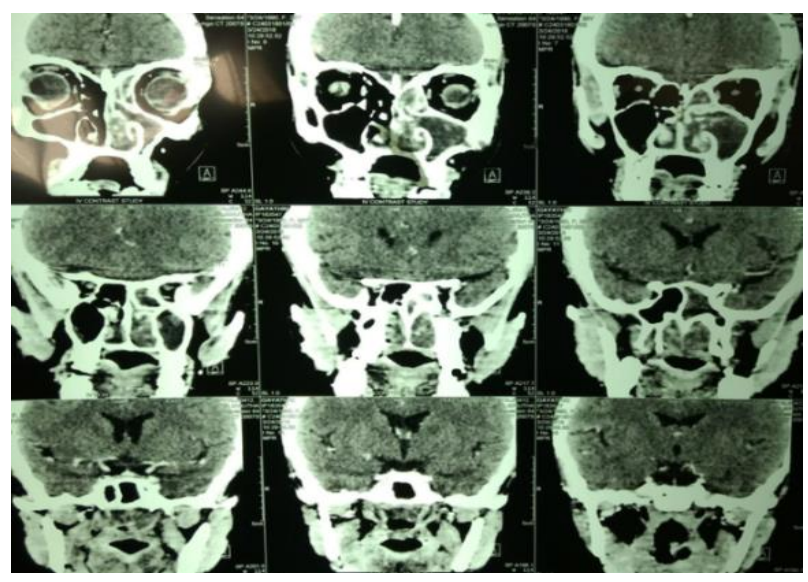

Figure 1: CT scan showing mass occupying left nasal middle meatus and extending into nasopharynx.

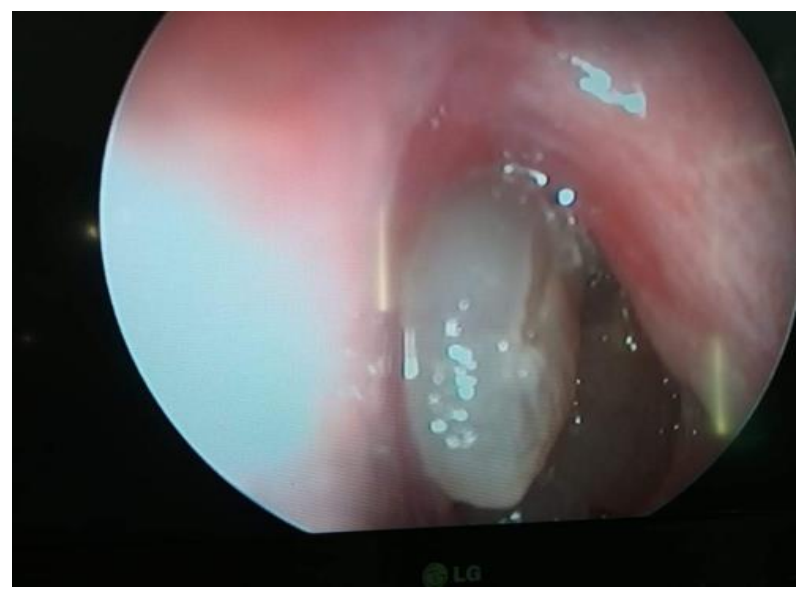

Figure 2: Transnasal endoscopy: mass noted in the left nasal meatus. Pedicle cauterized and removed in toto.

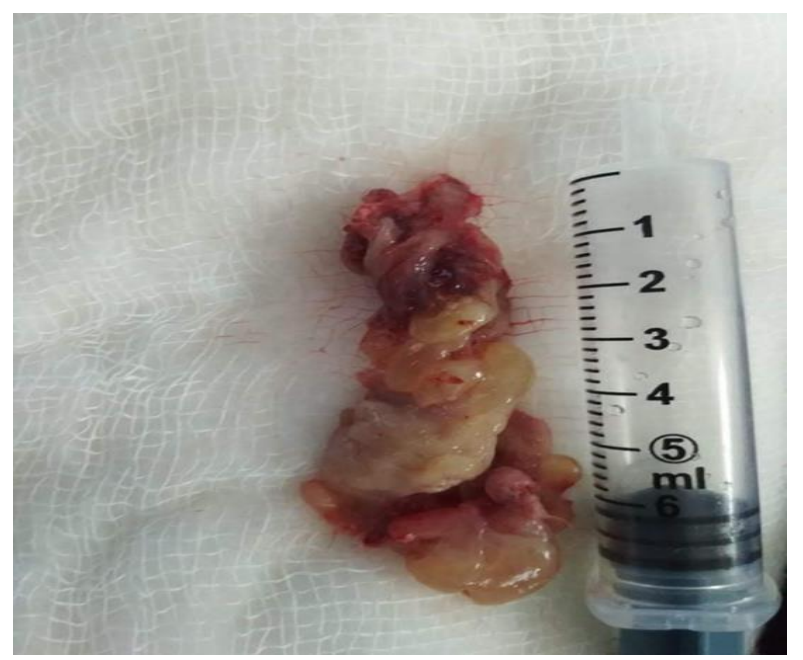

Figure 3: Gross specimen: fleshy mass with areas of necrosis.

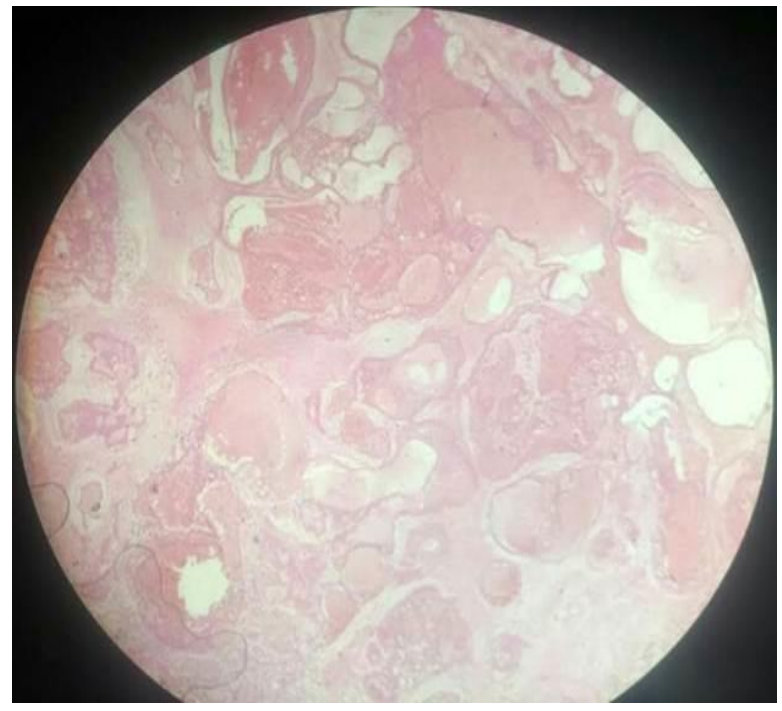

Figure 4: Histopathological examination: benign neoplasm with variable sized thin blood vessels suggestive of hemangioma.

\section{DISCUSSION}

Cavernous hemangiomas are composed of large endothelium lined vascular spaces. The mean age group of presentation is around 40 years with equal gender incidence. ${ }^{2}$ They usually present with recurrent epistaxis or hemoptysis with nasal obstruction. Nasal hemangiomas are predominantly capillary arising mainly from nasal septum. Cavernous hemangiomas are rare and reported to arise from inferior turbinate, middle turbinate and vomer. ${ }^{3}$ The differential diagnosis includes inverted papilloma, squamous cell carcinoma, adenocarcinoma, olfactoryneuroblastoma, lymphoma, lymphangioma, glomangioma, hemangiopericytoma and hemangioendothelioma. ${ }^{4}$

CT contrast and histopathological examination helps in definitive diagnosis. CT contrast will show the anatomical location, extension of the tumour with or without bony involvement. The growth would present as enhancing mass. Thrombus within the vascular spaces can occasionally calcify and form phleboliths which are considered to be typical of cavernous hemangioma. ${ }^{5}$

Nasal mucosa hemangiomas should be differentiated from hemangiomas arising from bones for deciding the surgical approach. The choice of surgical approach depends on site and extension of tumour. In case of intranasal hemangioma resection of the tumour with a part of surrounding uninvolved mucosa and cauterization of the feeding vessel is done. In tumour extending to the antrum, pterygomaxillary, infratemporal fossa, orbit, cheek and intracranial extension, wide approach may be required. Lateral rhinotomy, transantral, transpalatal, LefortI osteotomy and midfacial degloving may have to be done. ${ }^{6}$ In case of large hemangiomas, embolization of feeding vessels may be necessary. Recurrences occur late. Regular follow up is important to identify it. 
Funding: No funding sources

Conflict of interest: None declared

Ethical approval: Not required

\section{REFERENCES}

1. Archontaki N, Stanou AK, Hajiioannou JK, Kalonenopoulou N, Korkolis DP, Kyrmizakis DE. Cavernous hemangioma of the left nasal cavity. Acta Otorhinolaryngol Ictal.2008;28(6):309-11.

2. Iwata N, Hattori K, Tsujimura T. Hemangioma of the nasal cavity: clinicopathological study. Auris Nasus Larynx. 2002;29:335-9.

3. Amato B , Compagna R, Della Corte GA, Martino G , Bianco T , Coretti G, et al. Peripheral blood mononuclear cells implantation in patients with peripheral arterial disease: a pilot study for clinical and bio chemical outcome of neoangiogenesis. BMC Surge. 2012;12(suppl 1):S1.
4. Bakhos D, Lescanne E, Legeais M, Beutter P, Moriniere S. Cavernous hemangioma of the nasal cavity. Ann Otolaryngo Chir cervicofac. 2008;125(2):94-7.

5. Ito K, Nishimura K, Togashi K, Fujisawa I, Nakano $\mathrm{Y}$, Ito $\mathrm{H}$, et al. $\mathrm{RM}$ imagining of cavernous hemagioma of face and neck. J Compute Assist Tomogr. 1986;10:831-5.

6. Hayden RE, Luna M, Goepfert H. Hemangiomas of the sphenoid sinus. Otolaryngol Head Neck Surg. 1980;88:136-8.

7. Webb CG, Porter G, Sissons GRJ. Cavernous hemangioma of the nasal bones: an alternative management option. J Laryngol Otol. 2000;114:287-9.

Cite this article as: Thimmaiah $\mathrm{AH}$, Gangaraj SS, Paul TR. Cavernous hemangioma of left nasal meatus. Int J Otorhinolaryngol Head Neck Surg 2019;5:1115-7. 